\title{
Temporal and spatial patterns of the clinical surveillance of BSE in France, analysed from January 1991 to May 2002 through a vigilance index
}

\author{
Marie CUENOT $^{\mathrm{a}}$, Didier CALAVAS ${ }^{\mathrm{b}}$, David ABRIAL ${ }^{\mathrm{a}}$, Patrick GASQUi $^{\mathrm{a}}$, \\ Géraldine CAZEAU ${ }^{\mathrm{b}}$, Christian DUCROT ${ }^{\mathrm{a} *}$ \\ a Unité d'Épidémiologie Animale, INRA Theix, 63122 Saint-Genès-Champanelle, France \\ ${ }^{\mathrm{b}}$ Unité Épidémiologie, AFSSA Lyon, 31 av. T. Garnier, 69364 Lyon Cedex 07, France
}

(Received 2 August 2002; accepted 25 November 2002)

\begin{abstract}
Between 1991 and mid 2000, the surveillance of Bovine Spongiform Encephalopathy (BSE) in France was based solely on clinical surveillance through a Mandatory Reporting System. Since 2000, the implementation of active surveillance programmes using rapid tests, as a complementary tool targeted at dead and slaughtered cattle has shown that part of the BSE cases were not detected with the clinical surveillance. In order to obtain a better knowledge of the strength of the clinical surveillance, we analysed a vigilance index defined as the ratio of negative clinical suspicions to the cattle population in the region and period of interest. The temporal analysis of the vigilance index showed that it did not vary much between 1991 and 1999, increased sharply since 2000 , and then decreased partly in 2001. The geographical analysis of the variations of the vigilance index was performed at the department level by comparing the observed number of negative clinical suspicions per department to the expected number, computed on the basis of the national average index and standardised on the production type of the cattle - dairy versus beef suckling cattle. As assumed, the data followed a Poisson distribution. We observed a high geographical variation of the vigilance index: ten departments out of 91 presented a significantly higher vigilance index than the national one, and four a significantly lower vigilance index. The vigilance index showed that the clinical surveillance was heterogeneous during the past twelve years, both in time and geographic location, in a range of one to ten. So the apparent trend in the BSE epidemic during this period as well as the differences in the spatial incidence of BSE have to be analysed with caution.
\end{abstract}

BSE / epidemiology / surveillance / vigilance / cattle

\section{INTRODUCTION}

The surveillance of Bovine Spongiform Encephalopathy (BSE) started in December 1990 in France [23], based solely on clinical surveillance through a Mandatory
Reporting System (MRS). The MRS concerns the whole adult cattle population (aged two years or more). Suspect animals are those that display evocative clinical signs of BSE including alterations in behaviour, locomotion, hypersensitivity,

\footnotetext{
* Correspondence and reprints

Tel.: (33) 4736242 63; fax (33) 4736245 48; e-mail: ducrot@ clermont.inra.fr
} 
leading progressively and ineluctably to death. They are declared to the authorities by the veterinarians, either on the farm or at the abattoir (at the time of the antemortem examination). After euthanasia, the diagnosis is confirmed by histopathology or western blot on the brain stem. The development of so-called rapid tests allowed to carry out a pilot surveillance programme between June 2000 and March 2001, targeted at the cattle at risk, in order to complement the MRS in western France [12]. Then a systematic screening started in January 2001 for slaughtered cattle, and in June 2001 for fallen stock. These two programmes follow the European Union regulations and are running currently on the whole territory for every bovine aged two years or more.

So for nearly ten years, BSE has been only detected through the clinical surveillance of cattle. The efficiency of such a system depends on the conjunction of the training and awareness of both farmers and veterinarians, and their willingness to declare any suspect animal, given the stigma associated with the occurrence of the disease. These components can be summarised as the vigilance of farmers and veterinarians towards the disease. In the case of BSE, we can postulate that the vigilance might have varied strongly, depending on the number of cases detected in the geographical area of concern, the evolution of the knowledge concerning BSE among others the evidence of the link between BSE and a variant of the Creutzfeldt Jakob Disease (vCJD) - , and the media coverage. The same questions have arisen with other Transmissible Spongiform Encephalopathies (TSE), that may be difficult to identify or distinguish from other diseases. Concerning Scrapie for example, Hoinville [17] enhanced the fact that its distribution is difficult to determine accurately and may remain undetected unless comprehensive surveillance systems are in operation. For that disease affecting small ruminants, an anonymous postal survey carried out in Great Britain [16] showed that the level of underreporting might reach more than $85 \%$.

The lack of exhaustiveness of the BSE surveillance system in France was confirmed when active surveillance programmes started. Firstly, during the pilot programme targeted at cattle at risk (deadon-the-farm, emergency slaughtered or euthanasied) and carried out as a census in the second semester 2000 in western France [20], only $41 \%$ of the 83 BSE cases were detected with the MRS [13], the others were detected with the rapid tests on animals that were not declared as clinical suspects. A retrospective clinical investigation [3] showed that two thirds of the BSE cases found with the screening programme had displayed clinical signs before death, either characteristics or sufficiently suggestive, but for various reasons were not addressed to the MRS. This is consistent with the Swiss data [10]. Secondly, during the second semester of 2001, three programmes were run simultaneously in France: the MRS, the targeted screening of cattle at risk (fallen stock) and the systematic screening of slaughtered cattle. During this period, only $20 \%$ of the 178 BSE cases were found with the MRS, $49 \%$ with the targeted screening of dead cattle and $31 \%$ with the abattoir screening (Calavas, AFSSA, unpublished results).

So, because historical data from the clinical surveillance of BSE are of major importance to analyse the trend in the BSE epidemic in France, a better understanding of the strength of the clinical surveillance is needed. Two indices have been used or considered to evaluate the strength of the TSE surveillance. The first one is the ratio of negative suspicions to the animal population of concern, designed to compare the quality of the scrapie surveillance between countries [18]. It is based on the assumptions that: (i) the true incidence of neurological and locomotion disorders other than TSE is roughly comparable over time and between geographical areas, and 
(ii) the better the vigilance, the higher the number of animals declared as suspects among those that present neurological or locomotion signs due to other diseases than TSE. The second index is the ratio of definite to probable cases used by Will et al. [25] to compare the surveillance of CJD between countries. It depends both on the level of the epidemic and the incidence rate of other diseases that can be confounded with TSE, and is not easily used.

In order to investigate the variations of the French clinical surveillance of BSE, we used the ratio of negative clinical suspicions of BSE to the cattle population as a vigilance index towards BSE and analysed its variations over time and between French departments, from January 1991 to May 2002.

\section{MATERIALS AND METHODS}

\subsection{Vigilance index}

The vigilance index was defined as the ratio of negative clinical suspicions of BSE reported by the veterinarians to the adult cattle population in the area and period of interest. Only the negative suspicions were considered, i.e. those sent to the laboratory and not confirmed by histopathology or western blot, so that the index did not depend on the level of the BSE epidemic. The exposed cattle population was composed of all live cattle aged two years and more. It was approximated by the number of female cattle that had already calved, with the assumption that the proportion of males and young females does not vary between regions and from year to year in France.

\subsection{Data}

The database of clinical suspicions was supplied by the Agence Française de Sécurité Sanitaire des Aliments (AFSSA), in charge of BSE surveillance. All the clinical suspicions declared by the veterinarians from January 1991 to May 2002, either on the farm or at the abattoir, and not confirmed as BSE cases were taken into account. During the overall period of interest, $3 \%$ of the clinical suspicions could not be analysed given the poor quality of the brain sample; even if a great part of them might have been negative, they were excluded from the vigilance index numerator. The clinically suspect animals were classified in dairy versus beef cattle according to the breed. Crossbred bovines as well as those of mixed breeds were classified according to the production type of the farm, i.e. dairy versus beef cattle.

The data on the cattle population were provided by the Service Central des Enquêtes et Études Statistiques (SCEES) (Paris, France), according to the department and production type. We used the 1997 statistics [24] as a central point between 1991 and 2002, and because it provided the data required for the analysis.

\subsection{Analysis}

The evolution of the vigilance index on the overall French territory (excluding overseas territories and departments) was described by month and year. Given the hypothesis that the targeted screening programme on dead animals carried out in 2000 might have changed the vigilance of veterinarians and farmers, the vigilance index was plotted since 2000 distinguishing the western part of France - where the targeted programme was running - and the rest of France - where just a small sample of dead animals were tested during a short period of time [6].

The spatial variability of the vigilance index was adressed in the following way. First, a vigilance index per department (named $i=1, \ldots, n$ with $n=91$ ) was computed on the overall period (from January 1991 to May 2002). Then, the observed number of negative clinical suspicions in a given department $\left(o_{i}\right)$, was compared to the 
expected number $\left(e_{i}\right)$, assuming that the national average vigilance index was applied to the department [19].

The expected number of negative suspicions per department was performed by standardising the vigilance index on the production type, dairy versus beef cattle. The rationale is that beef suckling cows are known to be less affected by neurological disorders than dairy cows; this has been confirmed with a specialised neurological surveillance network carried out on 20 French veterinary practices [5], where the incidence of these health problems was 3.8 times higher in dairy cattle than in beef cattle (Calavas and Cazeau, unpublished results). Hence, with the same level of awareness and willingness to declare of veterinarians and farmers, one expects a lower vigilance index for beef cattle. Two separate vigilance indices were computed at the national level, one for dairy cattle (the ratio of negative suspicions concerning dairy cattle to the adult dairy cattle population), the other one for beef cattle. The expected number of negative clinical suspicions in each department was calculated in a two step procedure. We applied the national vigilance index appropriate for dairy cattle to the dairy cattle population size of the department and the national index appropriate for beef cattle to the beef cattle population size of the department. Both figures were summed up to obtain the expected number of negative suspicions in the department.

The comparison between the observed and expected values was based on the ratio of the observed to the expected number of negative clinical suspicions in a given department $\left(r_{i}=o_{i} / e_{i}\right.$, with $\left.i=1, \ldots, 91\right)$. This ratio, which we call the standardised vigilance ratio, is analogous to a Standardised Morbidity Ratio [2]. It helps in describing the data since it is higher than one if the vigilance index in a given department is higher than the national one, and lower than one in the opposite situation.
Given that clinical suspicions are rare events (very low percentage and large population size), the number of negative suspicions was assumed to follow a Poisson distribution with mean $e_{i} r_{i}$, where $r=\left(r_{1}, \ldots\right.$, $r_{n}$, with $n=91$ ) are the unknown area-specific standardised vigilance ratios. The comparison between the observed and expected numbers of negative clinical suspicions in each department was performed by considering, in a given department, that the observed number of negative suspicions is significantly higher (or lower) at the alpha level 5\% - than the expected number based on the national vigilance index, if the observed number is higher than the 97.5 percentile (or lower than the 2.5 percentile) of the Poisson distribution.

In order to verify the hypothesis that the number of negative suspicions followed a Poisson distribution, we globally compared the number of negative suspicions observed in the 91 departments to the expected number, under the Poisson assumption. For each of the 91 departments, we computed the probability to observe zero, one, up to 65 (maximum number observed) negative suspicions, separately for dairy and beef cattle, under a Poisson assumption and according to the dairy and beef cattle size in the department and the national vigilance indices for dairy and beef cattle. The probabilities to observe, respectively zero, one, up to 65 negative suspicions for dairy and beef cattle were added up for the 91 departments, which gave the expected number of French departments with zero, one, up to 65 negative suspicions, respectively in dairy and beef cattle, under the Poisson assumption. We performed a Chi square test to compare the observed and expected numbers of the departments with respectively zero, one, up to 65 negative suspicions, both for dairy and beef cattle. We pooled together classes when the computed number of the departments was lower than five. The number of degrees of freedom was the number of classes for dairy cattle minus one, plus the number of 


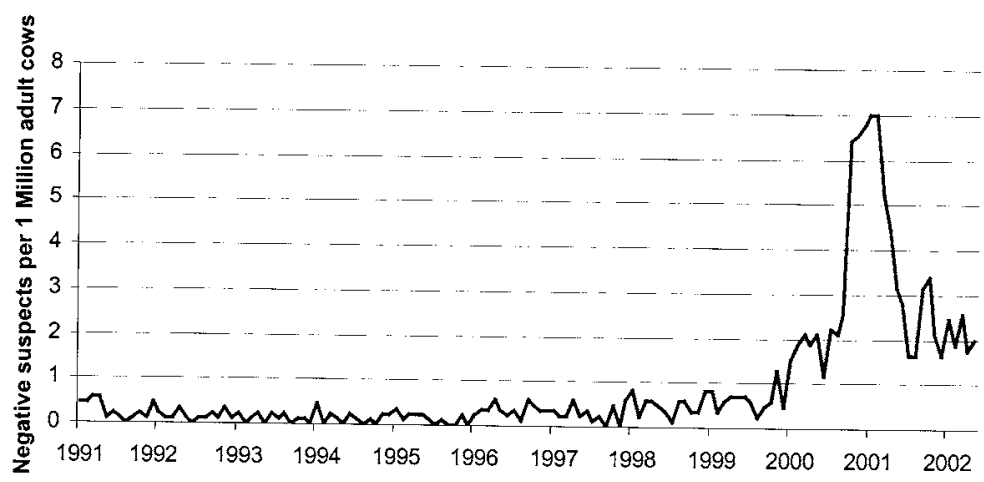

Figure 1. Monthly evolution of the BSE vigilance index in France from January 1991 to May 2002. The index was calculated as the ratio of the number of negative clinical suspicions of BSE reported to the Mandatory Reporting System, to the adult cattle population.

classes for beef cattle minus one, minus two for the two estimated parameters (national vigilance indices for dairy and beef cattle).

The data management was done using ACCESS (Microsoft Access 97 SR-2, Copyright (C) 1989-1997 Microsoft Corporation), the statistical analysis using S-Plus software (S-Plus 2000 Professional Release 2, Copyright (C) 1998-1999 Mathsoft, Inc., New York, USA), and the maps with Arc View software (Arc View 8 under Windows XP, Copyright (C) 2000 ESRI, Redlands, USA).

\section{RESULTS}

\subsection{Negative suspicions and vigilance index}

At the national level, and during the overall period, 1374 clinical suspicions were declared and brain samples were submitted for confirmation; 1048 were negative (76\%), 289 confirmed positive (21\%) and 37 could not be analysed (3\%). The negative suspicions concerned 786 dairy cattle $(75 \%)$ and 262 beef cattle $(25 \%)$.
The annual average vigilance index in France between 1991 and May 2002 was 10.7 negative suspicions per million adult cows per year (5.5 for beef cattle; 15.6 for dairy cattle).

\subsection{Temporal variation of the vigilance index}

The evolution of the vigilance index per month is shown in Figure 1. Until 1999, it varied between zero and one negative suspicion per million cows per month. Then, there was a sharp increase that started in December 1999 and reached a peak in December 2000, with 7 negative suspicions per million cows per month. The vigilance decreased in 2001 and then varied between 2 and 3 negative suspicions per million cows per month until mid 2002. The comparison of the vigilance index between western France and the rest of France since 2000 is shown in Figure 2. The curves were smoothed over a three month period to better visualise the trends because of the relatively small number of negative suspicions per month. The range of the vigilance index was in the same order between the two parts of France, but the trend was different; the vigilance index 


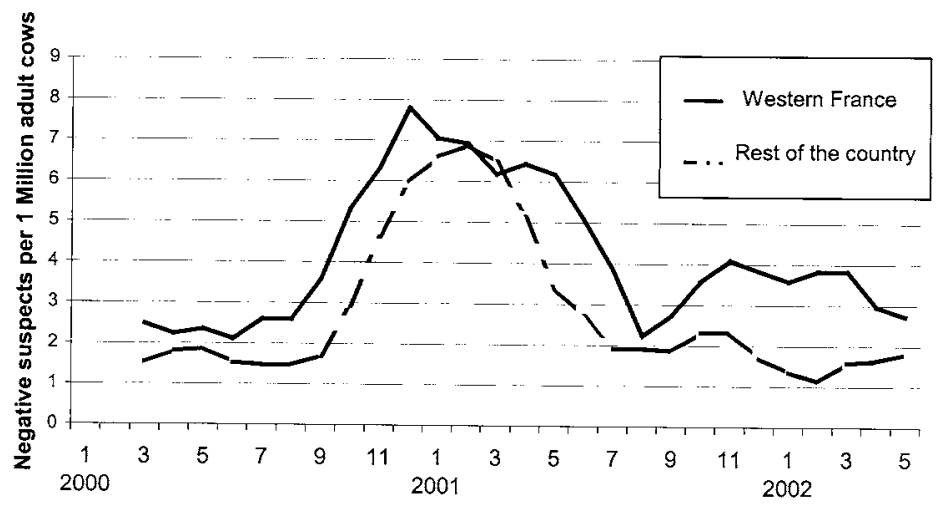

Figure 2. Comparison of the BSE vigilance index between western France (regions BasseNormandie, Bretagne and Pays de la Loire) and the rest of the country, from March 2000 to May 2002 (smoothed curves computed on a three month period).

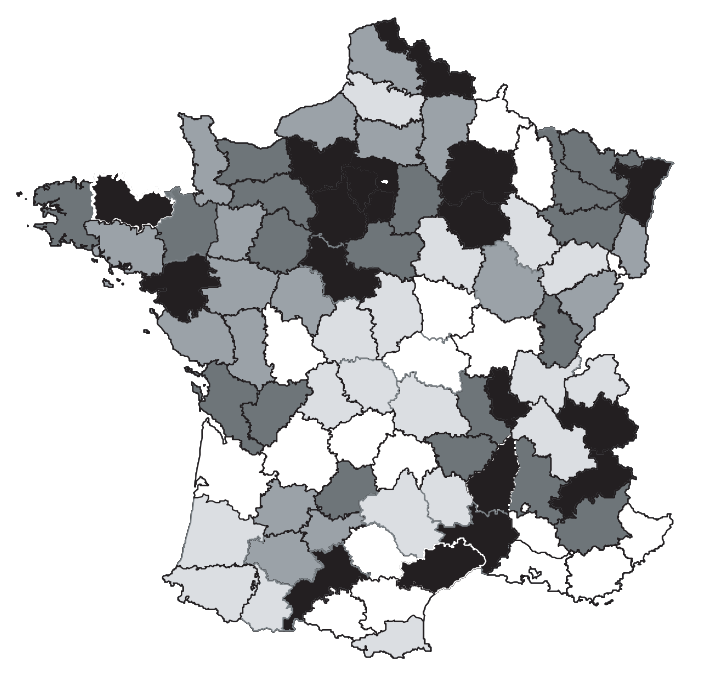

\section{Vigilance index}

Negative suspicions per one million adult cows per year (equal number of departments per category)

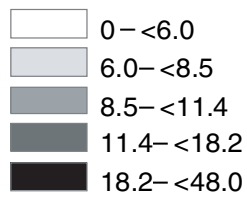

Figure 3. Distribution of the BSE vigilance index in 91 French departments with farming activities.

increased earlier and decreased later in western France.

\subsection{Geographical variation of the vigilance index}

The distribution of the crude vigilance index by department is presented in Figure 3 .
Figure 4 presents the distribution of the standardised vigilance ratio in the 91 departments, during the period of interest.

We tested the assumption that the number of negative suspicions followed a Poisson distribution. We classified the departments depending on the number of negative suspicions observed and expected 


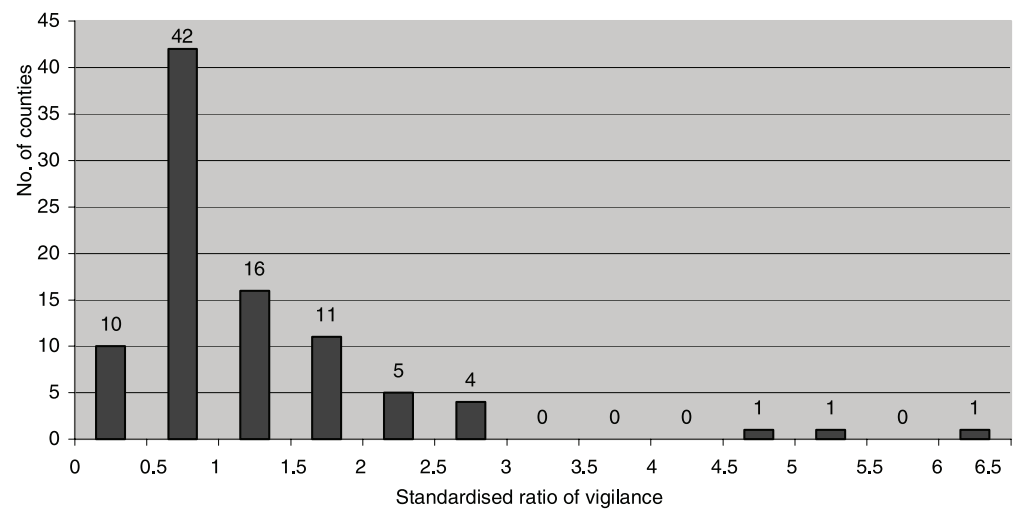

Figure 4. Distribution of the standardised vigilance ratio for the 91 French departments with farming activities (higher than one if the vigilance index is higher than the national vigilance index, and lower than one in the opposite situation).

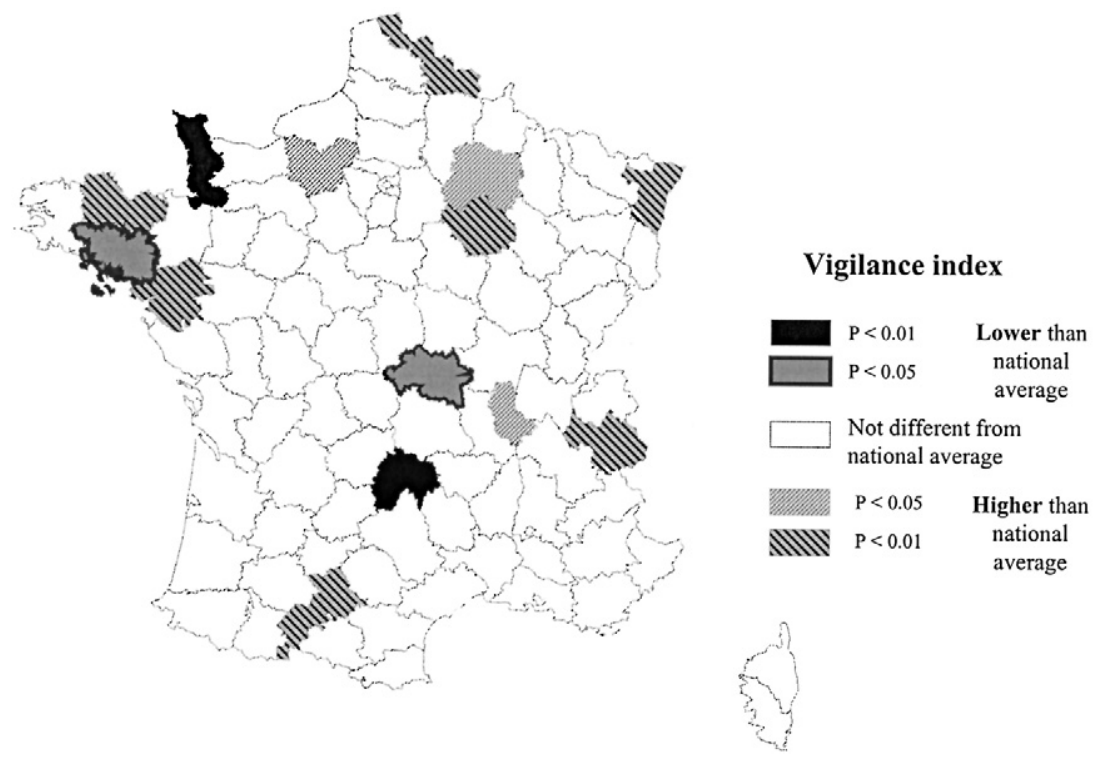

Figure 5. Comparison of the BSE vigilance index per department, standardised on the production type, with the national average index.

under the Poisson assumption. We used 13 classes for dairy cattle and eight for beef cattle. The Chi square value was 17.38 with 17 degrees of freedom. It was not significant (p-value 0.43), indicating that the observed data did not differ significantly from the expected number.
Figure 5 shows the departments that present a standardised vigilance ratio significantly different from one: ten departments out of 91 presented a significantly higher vigilance index than the national one, and four a significantly lower vigilance index. 


\section{DISCUSSION}

\subsection{Vigilance index}

As expressed in the introduction, the vigilance index is based on a first assumption that the incidence of neurological and locomotion troubles - other than those due to BSE - is roughly constant over time and between geographical areas. This might not be exactly the case, since some diseases showing signs close to those of BSE might have temporal and spatial variations in their incidence. However, different reasons should reduce the range of temporal and spatial variations in the incidence. First, the large range and variety of diseases sharing clinical signs with BSE and potentially resulting in negative suspicions of BSE should reduce the range of variation of the global incidence of neurological diseases. Second, the main temporal variation of these diseases is a seasonal one [5], that is not acting in an annual index. Third, those diseases with a specially high incidence in a given region are better known by veterinarians and should less frequently be confounded with BSE than others, which should reduce the spatial variation of the index. There are few data on the spatial and temporal variations of neurological diseases, and they might suffer from the same bias due to the vigilance of farmers and veterinarians. In Belgium, Saegerman et al. [22] observed a temporal variation of the annual incidence of reported neurological disorders in a range of one to two over a six year period of time. In our data, we can make the assumption that the range of variation of the vigilance index - one to ten - was greater than the range of variation of the incidence of neurological and locomotion disorders in France.

Though it is relatively poorly documented, one important point is the difference in the incidence of neurological disorders between dairy and beef cattle; this was the reason why we standardised the vigilance index on the production type. The annual average vigilance rate was three times higher for dairy cattle (15.6 negative suspicions per million cows per year) than beef cattle (5.5 negative suspicions per million cows per year), which may come from both the difference in the incidence of neurological disorders and the difference in the quality of the surveillance between dairy and beef cows by the farmers (dairy farmers watch their cows twice a day at milking). The latter point was confirmed [13] by data of the BSE surveillance in western France in 2000, when both the MRS and a test programme on cattle at risk were run simultaneously: 34 of the 75 cows from dairy herds affected with BSE were detected with the clinical surveillance, the others with the screening test, whereas none of the 13 other cows affected with BSE (nine from beef farms and four from mixed farms) were detected with the clinical surveillance (Chi square 10.7, 1df, p-value < 0.001).

The second assumption is that among the animals affected with neurological and locomotion disorders, the number of those that are reported to the MRS is indicative of the involvement of the farmers and veterinarians in the surveillance of BSE. More precisely, the vigilance index measures the combination of both the awareness to detect and willingness to declare. It cannot estimate separately these two conditions since they are both needed to report a suspect animal to the MRS. One could consider that the assumption might be wrong if veterinarians that are strongly aware and experienced with the disease could exclude most of the clinical suspects, on the basis of clinical signs only. However, it appears from the field experience [8] that the veterinarian practitioners highly aware of BSE consider that the clinical signs of BSE may vary strongly and that we must consider any neurological and locomotion trouble lasting for a certain period as suspect of BSE if no sure alternative aetiology has been evidenced. 
Another criticism of our vigilance index is that it only takes into account the suspicions that were judged sufficiently serious to be declared and not the suspicions checked by veterinarians and rejected. We tested that question first by comparing the number of clinical suspicions declared by veterinarians to the number of farm visits realised by veterinarians to observe an animal clinically suspect of BSE, given that up to four visits per animal can be recorded since they are paid to the veterinarian; these data, available per year on the overall French territory [9], came from the Ministry of Agriculture's records kept to pay the veterinarians for BSE surveillance. The number of farm visits cannot be taken as a quantitative base to evaluate the vigilance index, since each suspected animal can be visited several times. However, both figures show the same trend over time, which illustrates that our vigilance index is a reliable indicator of the veterinarian's activity towards BSE surveillance, even if it might underestimate the real level of veterinarian awareness. Another parameter to evaluate the vigilance index is the number of clinical suspicions that were seen by a specialised veterinarian - in each department a veterinarian is nominated to validate the clinical suspicions made by his colleagues - and rejected as a BSE suspect on the basis of the case history (not sent to the laboratory). The number of these rejected suspicions followed the same general trend as the vigilance index between 1998 and 2001 (Coudert, unpublished results), even if the increase between 1999 and 2001 was less dramatic.

The average surveillance index for the period and population of interest was 10.7 negative suspicions per million adult cows per year. This figure can be compared to the OIE recommendations for effective surveillance of BSE [21], that is to carry out a minimum number of 100 annual investigations of animals showing clinical signs compatible with BSE per million cattle over 30 months of age. This is ten times higher than the
French data during the period of interest, which indicates a probable lack of BSE surveillance in France at that period.

\subsection{Temporal variation of the vigilance index}

The vigilance index presents very high temporal variations, that can be partly linked to the implementation of complementary active surveillance programmes, as seen in Switzerland [10]. The vigilance increased when the first programme targeted at dead cattle started, then decreased to an average level that is roughly four times higher than before the screening programme and is still continuing in 2002, while the clinical surveillance and the screening of dead and slaughtered cattle coexists. This is consistent with other data [20] from the first targeted surveillance programme carried out in France in 2000. During the first three months, the ratio was one BSE case detected with the clinical surveillance to three with the rapid tests on dead animals, whereas it became one BSE case detected with the clinical surveillance to 0.7 cases with the rapid tests during the last three months; this could be due to the fact that veterinarians reacted to the situation by increasing their vigilance during the programme.

The vigilance index increased earlier in western France than in the rest of the country, and remained at a high level during a longer period. Western France is the first and one of the most affected areas with BSE in France, so farmers and veterinarians are certainly more aware of the disease. At the same time, the pilot programme on dead animals was organised there as a census in 2000, in opposition to the rest of France.

One of the main points issued from this analysis is that the vigilance of the farmers and veterinarians might have been at a low level in the early years of the French BSE epidemic, which raises concern about the accurateness of the surveillance data 
during that period. This is in agreement with back calculation [11] as well as ageyear-cohort models [7] carried out on the French data, that came to the conclusion that most BSE cases from the cohorts born in 1988-1990 were not detected; most of those animals might have died between 1992 and 1997, at a time where the vigilance index was the lowest.

A resulting question would be to discuss if the increase in the vigilance index really results in an increase in the efficiency to detect BSE. A simple way to address the question is to analyse the confirmation rate over time, i.e. the proportion of clinical suspicions that were confirmed positive at the laboratory. The confirmation rate varied between 18.2 and $30.1 \%$ since 1994 [1]. Even if the confirmation rate decreased from 30.1 to $23.6 \%$ between 1999 and 2001, it appears that the large increase in the number of clinical suspicions (from 91 in 1999 to 418 in 2000) resulted in a large increase in the number of BSE cases that were detected via the clinical surveillance (from 27 in 1999 to 99 in 2000). The number of detected cases is roughly proportional to the number of negative suspicions, which indicates that the vigilance ratio is a relevant indicator of the functionning and strength of the MRS.

\subsection{Spatial variation of the vigilance index}

The vigilance index shows a wide range of spatial variation. The annual crude vigilance index was close to zero in certain parts of France, and reached more than 40 negative suspicions per million cows per year in certain departments. As expected, geographical areas with the highest proportion of beef suckling cows present the lowest vigilance index, mostly in Central France. When standardised on the dairy versus beef cattle population, 14 departments of the 91 French departments with farming activities had a vigilance index significantly different (either higher or lower; $\mathrm{p}$-value $<0.05$ ) from the national average. The geographical location of these departments has no clear interpretation, and could be due to variations in the involvement of the people acting in the MRS at the department level. It suggests that the ability of the clinical surveillance system to detect BSE in the first decade of the French BSE epidemic was not the same everywhere, the ratio varying from one to ten.

It could have been useful to simultaneously analyse the temporal and spatial variations of the vigilance index, since we can postulate that the geographical variations changed over time. However, the small number of negative suspicions during the major part of the period of interest did not allow to carry out the analysis.

The analysis of the vigilance index showed that during the first decade of the French BSE epidemic, before 2000, the clinical surveillance was heterogeneous over time and space. The consequence of the variations in the vigilance rate is that the observed incidence of BSE is not comparable from year to year, so the apparent temporal trend of the epidemic has to be analysed with caution. In addition, the geographical variation in the observed incidence of BSE between departments has to be questioned since the strength of the surveillance system to detect BSE cases was not the same everywhere. Perhaps different correction strategies might be implemented, based on our results, in order to take into account the epidemiological biases due to the surveillance; they might give a more accurate idea of the spatial and temporal trends of the BSE epidemic in France.

The high variations of the vigilance between departments and over time, even from month to month, indicates the need for complementary measures in order to reinforce the strength of the clinical surveillance and to monitor its quality over time. Such measures could be based on the results of a detailed evaluation of the surveillance network [14] as recently 
performed for scrapie in France [15]. Such improvement of the BSE surveillance network would be of major importance in the future, if the incidence of BSE becomes so low that the systematic screening of dead and slaughtered cattle is not justified anymore [4].

\section{REFERENCES}

[1] AFSSA, Épidémiosurveillance de l'ESB en France. Tableau de bord, in: Afssa Documents [on line] (22 Oct. 2002) http://www.afssa.fr/ ftp/basedoc/TBseptembre2002.pdf [consulted 9 December 2002].

[2] Bouyer J., Hémon D., Cordier S., Derriennic F., Stücker I., Stengel B., Calvel J., Épidémiologie - Principes et méthodes quantitatives, Paris, 1995, 498 pp.

[3] Calavas D., Ducrot C., Programme pilote de surveillance de l'ESB. Enquête clinique rétrospective concernant les bovins positifs, in: Afssa Documents [on line] (22 May 2001) http://www.afssa.fr/ftp/basedoc/annexe2esb 30mai.pdf [consulted 9 December 2002].

[4] Calavas D., Savey M., Le réseau français de surveillance clinique de l'ESB. Passé, présent et avenir ? in: Journées nationales des Groupements Techniques Vétérinaires, Société Nationale des Groupements Techniques Vétérinaires, Tours, 2002, pp. 311-311.

[5] Calavas D., Desjouis G., Collin E., Schelcher F., Philippe S., Savey M., Incidence et typologie des maladies des bovins adultes à expression nerveuse en France. Le réseau pilote NBA, Epidémiol. Santé Anim. 39 (2001) 121-129.

[6] Calavas D., Morignat E., Ducrot C., Programmes de surveillance active de l'ESB dans trois catégories de bovins à risque. Analyse des résultats, in: Afssa Documents [on line] (29 May 2001) http://www.afssa.fr/ftp/ basedoc/syntheseresultatsesb.pdf [consulted 9 December 2002].

[7] Cohen C., Calavas D., Analyse des variations temporelles de l'incidence de l'ESB en France. Journées scientifiques de l'AFSSA, Maisons-Alfort, 27-28 March 2002.

[8] Collin E., Desjouis G., Calavas D., Baron T., Schelcher F., Troubles nerveux et ESB : Quand faire appel au vétérinaire coordonnateur ? in: Journées nationales des Groupements Techniques Vétérinaires, Société Nationale des Groupements Techniques Vétérinaires, Tours, 2002, pp. 313-314.
[9] Direction Générale de l'Alimentation, Santé animale : épidémiologie et prophylaxies bovines. Enquête statistique annuelle, in: DGAL, Paris, 1994 to 2000, 200 pp.

[10] Doherr M.G., Heim D., Fatzer R., Cohen C.H., Vandevelde M., Zurbriggen A., Targeted screening of high-risk cattle populations for BSE to augment mandatory reporting of clinical suspects, Prev. Vet. Med. 51 (2001) 3-16.

[11] Donnelly C.A., Likely size of the French BSE epidemic, Nature 408 (2000) 787-788.

[12] Ducrot C., Calavas D., Baron T., Madec J.-Y., Morignat E., Biacabe A.-G., Vinard J.-L., Roulet A., Étude de la prévalence de l'ESB grâce aux "tests rapides", Bulletin des GTV 9 (2000) 183-186.

[13] Ducrot C., Roy P., Morignat E., Baron T., Calavas D., How the surveillance system may bias the results of analytical epidemiological studies on BSE: prevalence among dairy versus beef suckler cattle breeds in France, Vet. Res. 34 (2003) 185-192.

[14] Dufour B., Technical and economic evaluation method for use in improving infectious animal disease surveillance networks, Vet. Res. 30 (1999) 27-37.

[15] Dufour B., Calavas D., Gauchard F., Plantady M., Évaluation du fonctionnement du réseau tremblante, Bulletin épidémiologique de l'AFSSA 5 (2002) 3-5.

[16] Hoinville L., McLean A.R., Hoek A., Gravenor M.B., Wilesmith J., Scrapie occurrence in Great Britain, Vet. Rec. 145 (1999) 405-406.

[17] Hoinville L.J., A review of the epidemiology of scrapie in sheep, Rev. Sci. Tech. OIE 15 (1996) 827-852.

[18] Hoinville L.J., Ducrot C., Doherr M.G., Second workshop on standardisation of the collection of epidemiological and clinical data, as part of the Concerted Action for setting up multicentric epidemiological databases and biological sample banks for small ruminant scrapie "European Scrapie Network" (No. FAIRJ-CT98-6056), in: Chalkidiki, Greece, 1999, 25 pp.

[19] Mollié A., Bayesian and empirical Bayes approaches to disease mapping, in: Lawson A., Biggeri A., Böhning D., Lesaffre E., Viel J.-F., Bertollini R. (Eds.), Disease mapping and risk assessment for public health Wiley, Chichester, 1999, pp. 15-30.

[20] Morignat E., Ducrot C., Roy P., Baron T., Vinard J.-L., Biacabe A.-G., Madec J.-Y., Bencsik A., Debeer S., Eliazsewicz M., Calavas D., Targeted surveillance to assess 
the prevalence of BSE in high risk populations and associated risk factors in western France, Vet. Rec. 151 (2002) 73-77.

[21] OIE, Surveillance and monitoring systems for bovine spongiform encephalopathy, in: International Animal Health Code, Appendix 3.8.4. [on line] (22 Aug. 2002) http:// www.oie.int/eng/normes/MCode/

A_00157.htm [consulted 9 December 2002].

[22] Saegerman C., Claes M., Vanopdenbosh E., Biront P., Deluyker H., Thiry E., Étude rétrospective de l'incidence des cas neurologiques rapportés et suspects d'encéphalopathie spongiforme transmissible chez les bovins en Belgique, Épidémiol. Santé Anim. 35 (1999) 31-42.

[23] Savey M., Belli P., Coudert M., Le réseau d'épidémiosurveillance de la BSE en France : principes — premiers résultats, Épidémiol. Santé Anim. 19 (1991) 49-61.

[24] SCEES, Agreste. Données chiffrées, Agriculture 112 (1998) 52-53.

[25] Will R.G., Alpérovitch A., Poser S., Pocchiari M., Hofman A., Mitrova E., de Silva R., D'Alessandro M., DelasnerieLauprêtre N., Zerr I., van Duijn C., Descriptive Epidemiology of CreutzfeldtJakob Disease in Six European Countries, 1993-1995, Ann Neurol 43 (1998) 763-767. 